\title{
Paul Herbig
}

\section{John Milewicz}

\author{
James E. Golden \\ Jacksonville State University \\ Jacksonville, Alabama
}

This paper reports the result of a study on American business forecasting, who does the forecasting, how often do they do forecasts, which areas are forecasted, what techniques are used, why they do it, and whether they are satisfied or dissatisfied with their forecasting efforts. We propose a set of hypotheses concerning forecasting behavior, provide results, provide conclusions, and make recommendations.

\section{Introduction to Forecasting}

Woody Hayes, the former Ohio State football coach, when asked why he believed in the three yards and a pile of dust rushing attack replied, "Because, when you pass the football three things can happen, two of which are bad." Managers have the same dread of forecasting that Woody had of the pass. Three things can happen when one forecasts, two of which are bad: one can over forecast or one can under forecast. Looking at forecasting at a time when they may need good forecasts more than ever, many managers are downplaying their importance. One reason may be that, like many other things, when forecasts are right, you don't hear about them. But when they're wrong....

Forecasting is predicting, projecting, or estimating some future event or condition which is outside of an organization's control and provides a basis for managerial planning. Organizations forecast so they can plan and help shape their future. Forecasting is a crucial input for planning in almost all companies. In a recent survey of 175 companies, $92 \%$ of the respondents indicated that forecasting was important for their company's success (Makridakis 1990). Forecasts are a major component of the business decision-making process. When accurate, estimates of future economic activity associated with specific courses of action can correctly guide corporate strategy in an uncertain environment; when inaccurate, they can bankrupt.

Forecasting plays an important role in every major functional area of business management. More companies probably undertake some form of forward estimation of their markets and their sales than of any other aspect of their activities. The estimates produced may then be used in a variety of ways, such as in production planning, planning the sales force, setting advertising appropriations, estimating cash flow, assessing the need for innovation or diversification, and in considering the general position of the company in the future. In marketing, forecasting is doubly important; not only does it have a central role in marketing itself, but marketing-developed fore- 
casts play a key role in the planning of production, finance, and other corporate activities.

Forecasting techniques range from simple to complex. All are intended to produce accurate, unbiased estimates of future activity in the presence of uncertainty. Applications of forecasting techniques can be improved as the forecaster gains experience and sophistication; however, there is always a risk that the forecaster's experience, expectations and hopes, among other things, may also introduce bias and error. Forecasting demand for new, complex, and rapidly changing high-technology products is particularly difficult, because of both limited experience and greater than usual number of unknowns.

Some useful generalizations about forecasting are as follows:

1. Forecasts are almost always wrong. The only real question is, by how much? Why then should one forecast bad numbers? A forecast is better than no forecast. In most businesses, a certain amount of error can be tolerated. This is called acceptable error, which varics from company to company, industry to industry. This variable depends on many factors including reaction time, size of company, and cost of an error to a company (Jain 1990).

2. The Time Horizons of Forecasting: The longer the time horizon of the forecasts, the greater the chance that established patterns and relationships will change, invalidating forecasts. Specifically, the more time competitors have to react to predicted events or the predictions themselves, the more able they will be to influence future events for their own benefit. Changes in the environment, including technology, competitors' strategy, buyer behavior, and government regulations, impact the long term. Farther into the future that one forecasts, the more likely unexpected environmental changes will occur. Many of these environmental changes cannot even be imagined for very long term predictions. If they cannot be imagined, they cannot be predicted and hence their effects on business can not be predicted either. Thus, all else being equal, forecasting accuracy decreases as the time horizons increase.

3. Technological Change: The higher the rate of technological change in a given industry, all other things being equal, the greater the chance that established patterns and relationships will change, and the greater the chance that competitors will be able to influence the industry through technological innovation. An excellent example is high-tech industries, where forecasting is almost impossible as firms strive to create the future according to their own conceptions. By bringing out new technologies, they hope to shape the future in desired directions in order to achieve competitive advantage. Thus, forecasting accuracy decreases as the rate of technological change increases.

4. Barriers to Entry: The lighter the barriers to entry, all other things being equal, the more inaccurate the forecasting, as new competitors (both domestic and foreign) can drastically change established patterns and relationships in their quest to gain competitive advantage.

5. Dissemination of Information: The faster the dissemination of information, all other things being equal, the less useful the value of forecasting, as everyone will have the same information and can arrive at similar predictions. In such a case it becomes 
impossible to gain advantages from accurate forecasting, as everyone else will also attempt to do so. However, those large firms which can organize information and disseminate it quickly to critical employees, would seem to have an advantage over those smaller organizations unable to do so.

6. Elasticity of Demand: The more elastic the demand, all other things being equal, the less accurate the forecasts. Thus, demand for necessities (for example, food items) can be predicted with a higher degree of accuracy than for non-necessities (such as vacationing). Obviously, people must eat and acquire necessities, which are given priority over other purchases in case of income reduction, as during periods of recession.

7. Consumer Versus Industrial Products: Forecasts for consumer products, all other things being equal, are more accurate than those for industrial products. Industrial products are sold to a few customers. If only one of those customers is lost, the rcsulting error can represent a substantial proportion of sales, because of the large qualities, or sales value, such customers buy. Those customers are well informed and can receive offers of bargain terms from competitors because of the large quantities or amounts they buy (Makradaris 1988).

8. Aggregate forecasts for families or groups of products are usually more accurate than item forecasts. This is true because the pattern of aggregate data does not change as rapidly as that of disaggregate (individual units). Insurance companies can reasonably predict how many auto accidents will occur in the United States next year or how many men age 40-50 will die, but not the particular individuals affected. On aggregate forecasts, some of the errors tend to cancel out; overestimates of some products cancel out underestimates of other products.

\section{Literature Review}

Examples of studies in the area of business forecasting policies and practices which have been done include those by: Dalrymple (1975), Dalrymple (1987), Mentzer and Cox (1984), Wheelwright and Clarke (1976), Sparkes and McHugh (1984), Rothe (1978), Rush and Page (1979), Cerullo and Avila (1975), Pokemper and Bailey (1970), Pan, Nichols, and Joy (1977), Mahmoud, et al. (1988), Piercy (1989), Mentzer (1988), Alsen, et al. (1989), Methews and Diamantpoulous (1986), and Wright (1988). These primarily have used only leading business firms, Fortune 500 American firms. Sample sizes have been relatively small. They predominantly used mail questionnaires.

The studies have addressed many forecasting issues. They suggest that dissatisfaction seems oriented more towards quantitative methods (Mentzer and Cox 1984) than qualitative. One fifth of firms have tried and rejected quantitative methods, twice as many as other techniques (Dalrymple 1987). Most companies aim for accuracy of within plus or minus 10 percent but only about $2 / 3$ of them achieved this goal (Mahmoud 1984). The average error is $6.9 \%$ (Dalrymple 1975). Forecasts based on opinions of the sales force and corporate executives gave less accurate results than did other methods. Quantitative techniques cost less and took less time (Mabert 1975). Quantitative 
methods provided better forecasts than judgmental methods (Dalrymple 1975; Cerullo and Avila 1975). However, Mahmoud (1984) indicated simple forecasting methods perform reasonably well in comparison to more sophisticated methods. Businesses tended to use qualitative techniques for shorter forecast durations while objective quantitative techniques for longer term (over 2 years) (Mentzer and Cox 1984; Dalrymple 1987). Industrial concerns prefer sales force composite over consumer firms (Dalrymple 1987). Industrial firms have higher error rates than consumer oriented firms (7.65\% on average versus 6.7\%) (Dalrymple 1975). Larger firms reported smaller errors than smaller firms (Dalrymple, 1987) which contradict previous results which indicate this did not vary inversely with the size of the firm (Dalrymple 1975). Sales Forecasts are typically prepared annually (Dalrymple 1975). The more people involved the more accurate the forecast (Dalrymple 1975). The most popular techniques over the past twenty years have been the Sales Force Composite and Jury of Executive Opinion. ${ }^{1}$ The naive model ${ }^{2}$ was third in popularity (Dalrymple 1987). Forecasting accuracy can be improved by combining techniques (Mahmoud 1984).

The most commonly used types of forecast include three main qualitative techniques: the Jury of Executive Opinion, Sales Force Composite, and Survey of Buying Intentions (Customers) ${ }^{3}$ and several quantitative ones including Trend Analysis (regression) and Market Share Analysis. The three qualitative techniques are the most commonly used by companies. All of these have their advantages and disadvantages and varying with the accuracy, costs, and lead time necessary, each has a particularly optimum usage in one or more situations.

\section{Hypotheses}

Based upon previous literature and generalizations from the forecasting literature, the following hypotheses appear reasonable:

Hypothesis 1: The larger the organization, the more likely it is to:

a: use objective techniques rather than subjective processes.

b: use quantitative forecasting processes rather than qualitative techniques.

c: use greater number of techniques compared to smaller firms.

$\mathrm{d}$ : have more people involved in the forecasting process.

1 Sales Force Composite is a "bottoms up" technique whereupon the sales force is queried to provide forecasts which are then compiled at the regional and national level into one integrated forecast.

Jury of Executive Opinion is a "tops down" forecasting technique whereupon senior management of a firm compile the forecast for the firm.

2 Naive model is where one uses the last period forecast (or results) as the forecast for this period without modification.

3 The Survey of Buyer (or Customer) intentions is simply to ask your customers what they think they will buy for the period being forecast. 


\section{Hypotheses (cont.)}

e: forecast externalities and competitive forces.

f: rate its forecasting process higher in importance and accuracy.

Hypothesis 2: The smaller the organization, the more likely it is to:

a: have greater executive involvement than larger organizations.

b: have greater use of simpler forecasting processes.

c: provide quicker feedback of results of the forecasting process.

Hypothesis 3: Manufacturers will tend to:

a: have fewer people involved in forecasting process than service-oriented firms.

b: have less executive involvement than service-oriented firms.

c: will tend to forecast more and rate more highly forecasts by product/brand product life cycle, and product line than service-oriented firms.

$\mathrm{d}$ : will tend to utilize more quantitative, complex, objective forecasting processes than service-oriented firms.

e: should rate forecasting more important and have higher accuracy levels than service-oriented firms.

f: should have longer duration of feedback between forecast and receiving results than do service-oriented firms.

$\mathrm{g}$ : should have more iterations in the forecasting process than do service-oriented firms.

\section{Hypothesis 4: Industrial-product firms:}

a: should use Jury of Executive Opinion and Sales Force Composite to a much greater extent than consumer-product firms.

b: should not be as quantitative, complex, or objective as consumer-product firms.

c: should not rate as highly or forecast competition as heavily as consumer-product firms.

d: should forecast industry trends, applications, and technologies to a much greater extent than do consumer-product firms.

e: should not have as high of satisfaction or accuracy in their forecasting processes as do consumer-product firms.

Hypothesis 5: Forecasting behavior should be different for worldwide-oriented firms than for domestic-focused firms.

Hypothesis 6: If forecasts are highly used in the managerial process than:

a: higher satisfaction of the process should result.

b: more executive involvement in the forecasting process should be seen.

c: more forecasting techniques should be used and more comparisons made among techniques.

\section{Methodology of the Study}

Data for this study was collected by mail survey with telephone follow-up to enhance sample size. A cover letter with university letterhead was utilized to provide 
legitimacy. The surveys were addressed to "Forecasting/Marketing" Manager to guide it to the most relevant respondent within the company. 1000 surveys were mailed to a sample of functioning entities. This sample included a randomly chosen 200 each from Leading 500 U.S. Industrial Concerns (Business Week), Services 500 (Fortune), the Forbes Top Small Businesses' List, the 500 Largest U.S.-based Multinationais (foreign headquarters) and 200 of the largest national non-profit/governmental affiliates. The sampling was randomized by selecting every nth listing. We varied the lists among the major three business periodicals (Fortune, Forbes, and Business Week) so as to eliminate any biases inherent in using just one.

A second mailing (of 500) was made after 60 days. This mailing was to nonrespondents with particular attention paid to under-sampled types of firms. This was followed by a random phone survey of non-respondents after an additional thirty days so as to encourage their involvement in the survey and to check for respondent versus non-respondent bias. One hundred and sixty-five (165) responses were received, of which 150 were usable for a response rate of $15 \%$.

Information of importance to this study was gathered via a 5 point bi-polar horizontal scale across eight dimensions. Respondents were asked to rate the output of their forecasting process on the basis of its: (1) simplicity, (2) understandability, (3) ease of usage, (4) comprehensiveness, (5) effectiveness, (6) timeliness, (7) accuracy, and (8) overall satisfaction with the forecasting process. Data were then analyzed by the use of factor analysis to assess whether each dimension assessed was indeed independent of the other dimensions.

Questions asked in the main body of the survey included who is involved in the preparation of forecasts for the surveyed company, type and frequency of forecast, importance and usage of forecasting techniques, uses of forecasted data within the company, number of iterations in the forecasting cycle, duration between forecast and availability of results, usage of more than one forecasting technique, a comparison of accuracy of forecast versus technique used, and who from a company is typically involved in the forecasting process. The questions were predominantly to be answered on a Likert-type scale or by checking the appropriate box. Several open-ended questions were also included which asked: what is the biggest outside influence and what information is found most useful, least useful, and which information of that surveyed should be examined in more detail. Organizational profile information requested included type of business, customer type, geographic area served, number of employees, company revenues, number of offices or plants, years in business, and years of forecasting experience for individual being surveyed.

\section{Results}

Table 1 profiles the respondents. In general, manufacturers and service firms responded while the response rate from non-profits and governmental entities was negligible. A balance between industrial and consumer firms was noted. The majority of the firms surveyed indicated they marketed principally in North America (not 
surprising a finding); however 45 firms indicated they were worldwide in their marketing efforts. A balance of small, medium and large firms was achieved as well as one between young firms and experienced firms.

\section{Table 1: Profile of Survey Respondents}

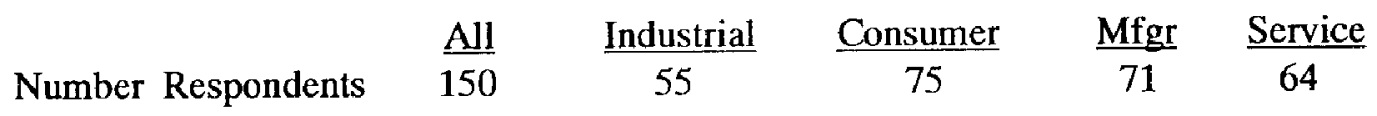

Size of Firm: $\$$ Revenues

$\begin{array}{llrrrr}<\$ 10 \text { Million } & 10 & 5 & 2 & 3 & 6 \\ \$ 10-100 \mathrm{M} & 35 & 13 & 15 & 22 & 8 \\ 100-500 \mathrm{M} & 31 & 12 & 14 & 14 & 12 \\ >\$ 500 \text { Million } & 66 & 22 & 42 & 28 & 35\end{array}$

Number of Employees

$\begin{array}{lrrrrr}1-100 \text { Small } & 8 & 7 & 1 & 2 & 6 \\ \text { 100-500 Mid } & 32 & 14 & 15 & 21 & 8 \\ 500-1000 \text { Med } & 15 & 1 & 9 & 9 & 3 \\ \text { 1000-5000 Large } & 41 & 17 & 20 & 18 & 20 \\ \text { >5000 Very Large } & 46 & 16 & 30 & 18 & 27\end{array}$

Sites: Offices/Plants

1 (single site)

$2-10$

15

7

6

85

$11-50$

52

23

23

34

15

$50-500$

13

16

11

18

7

23

$>500$

5

11

19

7

5

7

Years in Operation for Firm

$\begin{array}{ll}<10 & 15 \\ 10-40 & 5 \\ 40-100 & 5 \\ >100 & 2\end{array}$

$\begin{array}{rrr}8 & 8 & 5 \\ 25 & 26 & 22 \\ 30 & 23 & 28 \\ 11 & 11 & 8\end{array}$

Note 1: Columns do not necessarily add up due to non-response

Note 2: Differences between Total Sample and Consumer-Industrial firms; Mfgr-Service, are due to other categories not included.

A factor analysis of eight questions was completed regarding how the respondent rated the output of the forecasting process. The eight concepts were effectiveness, ease of use, accuracy, simplicity, meaningfulness, timeliness, understandability, and satisfaction with the process. Table 2 shows loadings. The factor analysis (principal components varimax rotation) performed on respondents' rating of their forecasting pro- 
cess produced two dominant dimensions. The two factors explain nearly $63 \%$ of the variance. Factor one, "simplicity," consists of simplicity, understandability, and ease of usage. Factor two, "usefulness," consists of meaningfulness, effectiveness, timeliness, accuracy, and satisfaction. It is important and interesting to note that satisfaction with the forecasting process clearly is related not to its ease of use but to the effectiveness and usefulness of the process as a whole.

\section{Table 2: Results of Factor Analysis}

\begin{tabular}{|c|c|c|c|c|}
\hline Variable & Factor 1 & Factor 2 & Factor 3 & Factor 4 \\
\hline Simplicity & $* 0.592$ & ${ }^{*} 0.463$ & 0.340 & -0.410 \\
\hline Understandability & -0.087 & $* 0.870$ & -0.241 & -0.005 \\
\hline Ease of Use & -0.118 & $* 0.852$ & -0.202 & 0.129 \\
\hline Meaningfulness & $* 0.845$ & 0.052 & 0.176 & 0.062 \\
\hline Effectiveness & $* 0.846$ & -0.010 & 0.064 & 0.282 \\
\hline Timeliness & $* 0.561$ & -0.280 & -0.359 & -0.380 \\
\hline Accuracy & $* 0.747$ & 0.053 & -0.179 & 0.440 \\
\hline Satisfaction & $* 0.746$ & -0.023 & 0.133 & -0.269 \\
\hline Eigenvalues & 3.096 & 1.918 & 0.733 & 0.679 \\
\hline $\begin{array}{l}\% \text { Variance } \\
\text { Explained }\end{array}$ & 38.69 & 23.97 & 9.1 & 8.4 \\
\hline
\end{tabular}

Table 3 discusses the summary of results for Hypothesis 1; Table 4 discusses the summary of results for Hypothesis 2. It appears the larger the company, the more people involved; the larger the firm, the higher importance given and more often does the company use complex quantitative techniques; the larger the firm, the more objective it becomes in the forecasting process; the larger the firm, the more attuned and alert the firm is to external influences; the larger the firm, the more the firm tends to forecast facility needs; the larger the firm, the more the firm will tend to forecast by geographical region; and the more employees, the more complex the forecasting process tends to become.

On the other hand, the smaller the company, the more executives which are involved in forecasting process. Small firms tend to use more subjectivity in the forecasting process than either large firms or medium sized firms. Smaller firms tend to rate their ease of use of the forecasting process and its results higher than do either medium or larger firms. Although smaller firms have quicker turnaround between forecast and results received than do larger firms, mid-sized firms appear to have best and quickest results. Similarly, medium-sized firms rate the importance and accuracy of forecasting by product line higher than smaller firms which in turn rate it higher than 
large firms. Likewise, medium-sized firms rated the importance and accuracy of forecasting by application higher than smaller firms and larger firms.

\section{Table 3: Summary of Results: Hypothesis 1}

H 1a: The larger the firm the more objectivity (less personal subjectivity) exists in the forecasting process $(\mathrm{F}=5.872, \mathrm{p}<.017)$.

1b: The larger the firm, the higher the importance given and more often does the company use complex quantitative techniques $\left(X^{2}=7.621 ; \mathrm{p}<.029\right)$.

1c: The more employees a firm has, the more branches/offices a firm has, the more complex the forecasting process tends to become $\left(X^{2}=16.328 ; \mathrm{p}<.01\right)(F=4.633$, $\mathrm{p}<.008)$.

1d: The larger the firm, the more people involved in the forecasting process $\left(X^{2}=24.971 ; p<.003\right)$.

1e. The larger the firm, the more employees a firm has, the more branches/ offices a firm has, the more the firm tends to forecast externalities $\left(X^{2}=9.298 ; p<.026\right)$; $\left(X^{2}=9.452 ; p<.030\right)\left(X^{2}=10.581 ; p<.014\right)$.

1f: The longer a firm has been in business, The larger the firm the more confident it is of its forecasting system $\left(\mathrm{X}^{2}=6.21 ; \mathrm{p}<.039\right)(\mathrm{F}=5.182, \mathrm{p}<.023)$.

1g: The more branches/offices a firm has, the more the firm tends to forecast competition $\left(\mathrm{X}^{2}=10.131 \mathrm{p}<.018\right)$.

\section{Table 4: Summary of Results for Hypothesis 2}

H 2a: The smaller the organization, the greater the executive involvement $\left(X^{2}=\right.$ $12.787 ; \mathrm{p}<.012$ ).

***2b: The smaller the organization, the greater the ease of use of the forecasting process $(F=3.388, p<.037)$. Smaller firms do indicate greater ease of use than larger firms but medium sized firms significantly show higher than both.

***2c: The smaller the organization, the quicker the feedback of forecasting results $\left(X^{2}=12.64, p<.013\right)$. Smaller firms do have quicker feedback than larger firms but once again medium sized firms respond quicker than either small or large firms.

Note: $A^{*}$ indicates non-significance of results; $a{ }^{* *}$ indicates a contrary finding and ${ }^{* * *}$ indicates an interesting sidenote.

Table 5 summarizes the results from Hypothesis 3. Similarities between manufacturers and service-oriented firms were few. Both groups reported similar interest and frequency in forecasting by customers, by applications, by geographical region, by competition, and by industry trends. Both groups reported similar perceived levels of forecasting complexity, forecasting comprehensibility, forecasting meaningfulness, forecasting effectiveness, and forecasting accuracy in their forecasting processes. 


\section{Table 5: Summary of Hypothesis 3 Results}

H 3a: Manufacturers tend to have fewer employees involved in the forecasting process than do service-oriented firms $\left(X^{2}=11.933 ; p<.018\right)$.

3b: Manufacturers tend to have less executive involvement in the forecasting process than do service-oriented firms $\left(X^{2}=16.455 ; \mathrm{p}<.039\right)$.

***3c: Manufacturers tend to more extensively utilize, view as important $\left(\mathrm{X}^{2}=28.879 ; \mathrm{p}<.012\right)$, and estimate higher accuracy on forecasting by product/brand $\left(\mathrm{X}^{2}=14.536 ; \mathrm{p}<.001\right)$, product line $\left(\mathrm{X}^{2}=7.259 ; \mathrm{p}<.027\right)$, and product life cycle $\left(\mathrm{X}^{2}=\right.$ $18.729 ; \mathrm{p}<.005)$. However, those service firms which do forecast by products, tend to rate their forecasting by product line to be more accurate than do manufacturers $\left(\mathrm{X}^{2}=10.692 ; \mathrm{p}<.030\right)$ as well as more frequent $\left(\mathrm{X}^{2}=21.89 ; \mathrm{p}<.001\right)$.

**3d: Manufacturers do not tend to have more quantitative, complex, subjective $(\mathrm{F}=5.872 ; \mathrm{p}<.016)$ forecasting techniques than do service-oriented firms. Service firms tend to use more regularly the weighted moving average technique than do manufacturers $\left(X^{2}=17.040 ; p<.009\right)$. Manufacturers tend to use more regularly the Sales Force Composite forecasting technique $\left(X^{2}=14.601 ; p<.001\right)$ and the Jury of Executive Opinion forecasting technique $\left(\mathrm{X}^{2}=31.182 ; \mathrm{p}<.001\right)$ than do service-oriented firms, both highly qualitative, subjective processes.

3e: Manufacturers tend to rate higher importance to forecasting process than do service oriented firms $\left(\mathrm{X}^{2}=4.077, \mathrm{p}<.043\right)$. A significant difference exist between both groups in their rating of satisfaction $(F=5,182, p<.023)$ as well as in the two groups' perception of ease of use $(\mathrm{F}=6.28, \mathrm{p}<.015)$. Service-oriented firms do rate their forecasting process as more accurate than do manufacturers $\left(\mathrm{X}^{2}=13.234 ; \mathrm{p}<.030\right)$.

**3f: Service firms do not have shorter duration of feedback between forecast and receiving results $\left(X^{2}=16.160 ; p<.013\right)$ but do rate their forecasting output as more timely than do manufacturers $\left(X^{2}=10.410 ; p<.035\right)$.

3g: Manufacturers do have more iterations in the forecasting process than do service-oriented firms $\left(X^{2}=21.42 ; p<.011\right)$.

Several significant differences were found between manufacturers and service-oriented firms. Manufacturers tended to have more iterations in the forecasting process and to provide quicker forecasting feedback of results to users of the forecast. They tend view Sales Force Composite as the most important forecasting technique with Jury of Executive Opinion as the second most important technique. They tend to use more frequently, and rate more highly, forecasts according to: product line, product life cycle analysis, and by product or brands. Manufacturers tend to have a higher level of overall satisfaction with the forecasting process and to rate the forecasting process higher in its importance and relative level of accuracy than do service-oriented firms. Nonetheless, contrasting to what was predicted, manufacturers do not tend to use more quantitative (objective) techniques in their forecasting process than do service-oriented firms.

Service-oriented firms, on the other hand, tend to have more people involved in the forecasting process with a higher percentage of executive involvement. They tend 
to view weighted moving average as an important forecasting technique and be less likely to forecast by product line. Although they rated their forecast output as more timely than do manufacturing firms, feedback to users tends to take longer. Serviceoriented firms tended to use subjective forecasting processes to a much higher degree than manufacturers. Whether related or not, service-oriented firms reported that their forecasting process tends to be more cumbersome, they are less satisfied with the output of the forecast process, and thus have a tendency to rate forecasting less important than do manufacturing firms.

Table 6 summarizes the results for Hypothesis 4 . We had expected to see great differences in the forecasting behavior between industrial-oriented firms and consumeroriented firms. This was not the case in that more similarities than differences were observed. We observed that the number of people involved and their levels within the company tend to be similar for both consumer-oriented firms and industrial-oriented firms. Both groups indicated similar number of iterations in their forecasting process as well as a similar duration before feedback results were available to users. The level of subjectivity within the forecasting process and general overall level of satisfaction with the forecasting processes were similar.

\section{Table 6: Summary of Results for Hypothesis 4}

H 4a: Industrial oriented firms utilize Sales Force Composite $\left(X^{2}=13.19 ; \mathrm{p}<.001\right)$ and Jury of Executive Opinion $\left(\mathrm{X}^{2}=12.356 ; \mathrm{p}<.002\right)$ forecasting techniques more often than do consumer-oriented firms.

*4b: Consumer-oriented firms do not tend to use more complex, quantitative, objective forecasting techniques than do industrial-oriented firms. No significant differences found in forecasting behavior. Consumer oriented firms, however, do put much lower importance on exponential smoothing techniques than do industrial firms $\left(\mathrm{X}^{2}=7.474 ; \mathrm{p}<.024\right)$.

**4c: Consumer-oriented firms tend not to forecast more often nor place higher importance on forecasting competition $\left(X^{2}=6.72 ; p<.035\right)$.

* $4 \mathrm{~d}$ : Industrial-oriented firms tend to forecast more often and place higher importance on forecasting industry trends $\left(X^{2}=9.819 ; p<.007\right)$, applications $\left(X^{2}=6.643\right.$; $\mathrm{p}<.036$ ), and technologies $\left(X^{2}=26.927 ; \mathrm{p}<.001\right)$ but not necessarily customers (not significant).

${ }^{*} 4 \mathrm{e}$ : Consumer-oriented firms should have greater accuracy $\left(X^{2}=7.893 ; p<.026\right)$ but not necessarily satisfaction (not-significant) in their forecasting process.

However, several significant differences between the two groups were found. Consumer-oriented firms believe their forecasting processes exhibit greater accuracy than do industrial firms. Consumer-oriented firms put much lower importance on exponential smoothing. Consumer-oriented firms do not use Sales Force Composites as often as do industrial oriented firms. Consumer firms do not competitively forecast nor do they forecast industry trends as often as do industrial firms. 
Industrial-oriented firms, on the other hand, rated Sales Force Composite much higher in importance and usage than did consumer firms. Competitive forecasting is done more often and considered more important by industrial oriented firms than by consumer firms. Forecasting industry trends tends to be more often used and more highly rated by industrial oriented firms than by consumer firms. Industrial firms tend to forecast more by application than do consumer firms. Industrial firms rated their forecasting process as more easier to understand than did consumer firms.

The fifth hypothesis, forecasting behavior is different for worldwide-oriented firms than it is for domestic-focused firms, was tested by comparing self-report responses from firms who declared themselves North-American-focused and those declaring themselves worldwide-oriented in their geographic coverage. Many similarities were found between the two groups. Both groups reported similar number of iterations in the forecasting process and duration before results are available to users. Both groups indicated the number of people involved and the levels of involvement were similar. Agreement was also found in the forecasting techniques used and the importance of forecasting techniques in the forecasting process.

Several significant differences were found in forecasting behavior between the two groups. North American-focused firms tended to less frequently forecast by customers $\left(\mathrm{X}^{2}=14.603 ; \mathrm{p}<.002\right)$, by geographical region $\left(\mathrm{X}^{2}=17.735 ; \mathrm{p}<.001\right)$, by product line $\left(X^{2}=9.460 ; p<.024\right)$, and by product or brands $\left(X^{2}=9.655 ; p<.022\right)$ than did worldwide-oriented firms. Nonetheless, North American-focused firms tended to perceive greater accuracy in their forecasting of applications $\left(\mathrm{X}^{2}=12.328, \mathrm{p}<.001\right)$, products $\left(\mathrm{X}^{2}=9.731 ; \mathrm{p}<.027\right)$, and product lines $\left(\mathrm{X}^{2}=3,587, \mathrm{p}<.058\right)$ than did worldwide-oriented firms.

Worldwide-oriented firms, on the other hand, reported to have more complex and less easily understood forecasting processes. Worldwide-oriented firms also report to have less meaningful $(F=5.162, p<.007)$ and easy-to-use $(F=3.469, p<.034)$ forecasting processes than do North American-focused firms. Worldwide-oriented firms rated the importance and accuracy of forecasting competition much lower than do North American-focused firms. Interestingly, worldwide-oriented firms indicate less effective $(\mathrm{F}=4.457, \mathrm{p}<.013)$ and less timely forecasting processes than did North American-focused firms. Also, paradoxically, North American-focused firms indicated their level of accuracy $\left(\mathrm{X}^{2}=6.137, \mathrm{p}<.013\right)$ and satisfaction $(\mathrm{F}=3.493, \mathrm{p}<.035)$ to be much higher than worldwide-oriented firms.

Finally, hypothesis 6 was also confirmed. The greater utilization in the managerial process for forecasting processes within a firm, the higher satisfaction there is with the forecasting process $\left(\mathrm{X}^{2}=23.857 ; \mathrm{p}<.001\right)$. The greater utilization in the managerial process for forecasting processes within a firm, the more executive involvement within the forecasting process $\left(X^{2}=11.784 ; p<.001\right)$. The greater utilization in the managerial process for forecasting processes within a firm, the more forecasting techniques are used and more comparisons among techniques $\left(X^{2}=10.704 ; p<.001\right)$. 


\section{Conclusions and Implications}

The general implications of the exploratory forecasting study are a verification of previous results. Prior research has noted that the Sales Force Composite and Jury of Executive Opinion techniques are predominant for industrial concerns. Our findings indicate this preference can be extended as well to manufacturers over service-oriented firms. Of new interest is the fact that products and brands appear to be still considered the domain of goods producers (manufacturers) as forecasts revolving around products-products, product line, product life cycles-still remain heavily and predominantly used by manufacturers and not service firms. This may indicate a weakness in service-oriented firms since they are not looking at their market in a product-by-product, brand way.

Interestingly enough, although more people are involved in the forecasting process and at higher levels for service-oriented firms, manufacturers tend to have more iterations, faster feedback, and more general satisfaction with the overall forecasting process than do service firms. This could be traced to the intangibility of the service firm's products and the difficulty in forecasting intangibles. This weakness could also be a source of potential for marketing firms wishing to do business with service entities. Providing greater ease, accuracy, and utilitarianism to the forecasting process for service-oriented firms appears to be a highly demanded latent product.

The most surprising finding was the high level of agreement in most questions between consumer product firms and industrial product firms. We would expect to see considerable contrast due to the different classes of customers. This, though, was not so. In virtually every other category, no differences between the groups were noted. Even the factor analyses were nearly identical. Perhaps, contrary to popular opinion, the two groups might be more similar in behavior than different, at least for forecasting. None of the industrial product firms predominantly used Sales Force Composite and Jury of Executive Opinion, confirming previous research. Industrial product firms were found to use more often and value more highly forecasting by industrial trends, competitive analysis, and applications. Consumer product firms believe their forecasting accuracy is higher than industrial firms, confirming previous research.

Another interesting and crucial finding is the fact that North American-focused firms do less forecasting by product/brand, product line, application, customers and geographical region than do worldwide-oriented firms. They also report greater confidence in forecasting accuracy for those items. North American-focused firms indicate greater feelings of meaningfulness, ease of use, effectiveness, satisfaction and importance for the forecasting process than worldwide-oriented firms. Yet, as many a result shows, performance, in terms of competitive superiority, is the reverse. Perhaps the arrogance that made many an American firm fall victim to aggressive international competition can also be seen in forecasting. Less optimism and more realism might be more appropriate. If the North American-focused firms are actually doing a better job in the forecasting process, than there can be no excuse for being caught unprepared and surprised competitively. 


\section{References}

Alsem K.J., P.S.H. Leeflang and J.C. Reuyl. 1989. “The Forecasting Accuracy of Market Share Models Using Predicted Values of Competitive Marketing Behavior." International Journal of Research in Marketing 6:3: 183-198.

Armstrong, J.S. 1985. Long Range Forecasting: From Crystal Ball to Computer. New York: John Wiley \& Sons.

Ayres, Robert U. 1989. "The Future of Technological Forecasting." Technological Forecasting and Social Change 36 (August): 49-61.

Barnett, F. William. 1988. "Four Steps to Forecast Total Market Demand." Harvard Business Review (July/August): 28-35.

Cerullo, Michael J. and Alfonso Avila. 1975. "Sales Forecasting Practices: A Survey." Managerial Planning 24: 33-39.

Chambers, J.C., S.K. Mullick and D.D. Smith. 1971. "How to Choose the Right Forecasting Technique." Harvard Business Review 49 (July-August): 45-71.

Compton, Joan Callahan and Stephen S. Compton. 1990. Successful Business Forecasting. Blue Ridge Summit PA: Liberty Hall Press.

Cox, Jr., James E. 1989. “Approaches for Improving Salespersons' Forecast." Industrial Marketing Management 18: 307-311.

Dalrymple, Douglas J. 1975. "Sales Forecasting Methods and Accuracy." Business Horizons (December): 69-73.

1987. "Sales Forecasting Practices." International Journal of Forecasting 3: $380-391$

Davis, J. 1987. "Techniques and Marketing Forecasting." Management Decision 25 (3): 62-71.

Einhorn, Hillel J. and Robin M. Hogarth. 1982. "Prediction, Diagnosis, and Causal Thinking in Forecasting." Journal of Forecasting 1: 23-36.

Evans, Jonathan St. 1982. "Psychological Pitfalls in Forecasting." Futures (August): 258-265.

Flores, Benito E. and D.C. Whybark. 1985. "Forecasting Laws for Management." Business Horizons (July/August): 48-52.

Georgoff, David M. and Robert G. Murdick. 1986. "Manager's Guide to Forecasting." Harvard Business Review (January/February): 110-120. 
Gerstenfeld, A. 1971. "Technological Forecasting." Journal of Business 44:1 (January): 10-18.

Hogarth, Robin M. and Spyros Makridakis. 1981. "Forecasting \& Planning: An Evaluation." Management Science 27: 115-138.

Jain, C.L. 1990. "Myths and Realities of Forecasting." The Journal of Business Forecasting Methods and Systems 9 (Fall): 18-22.

Kamakura, Wagner A. and Siva K. Balasubramanian. 1987. "Long Term Forecasting with Innovation Diffusion Models: The Impact of Replacement Purchases." Journal of Forecasting 6: 1-19.

Klopfenstein, Bruce C. 1989. "Forecasting Consumer Adoption of Information Technology and Services: Lessons from Home Video Forecasting." Journal of the American Society for Information Science 40 (January): 17-27.

Lewis, C.D. 1982. Industrial and Business Forecasting Methods. London: Butterworth Scientific.

Lilien, Gary L. 1987. “Business Marketing: Present and Future.” Industrial Marketing and Purchasing (UK) 2:3: 3-21.

Mabert, V.A. 1978. "Forecast Modifications Based Upon Residual Analysis." Decision Sciences 9:2 (April): 285-296.

Mahmoud, Essam. 1984. “Accuracy in Forecasting: A Survey." Journal of Forecasting 3: 139159.

Mahmoud, E., G. Rice and N. Malholtra. 1988. "Emerging Issues In Sales Forecasting and Decision Support Systems." Journal of the Academy of Marketing Science 16:3/4 (Fal1): 4761.

Makridakis, Spyros G. 1990. Forecasting: Planning and Strategy for the 21st Century. New York: Free Press.

and Steven C. Wheelwright. 1977. "Forecasting: Issues and Challenges for Marketing Management." Journal of Marketing (October): 24-37.

Mathews, B.P. and Diamantopoulos. 1986. "Managerial Intervention In Forecasting. An Empirical Investigation Of Forecast Manipulation." International Journal of Research in Marketing 3:1: 3-10.

McLaughlin, Robert L. 1983. "Forecasting Models: Sophisicated or Naive?" Journal of Forecasting 2: 274-276.

Mentzer, J.T. and J.E. Cox, Jr. 1984. "Familiarity, Application, and Performance of Sales Forecasting Techniques." Journal of Forecasting 3: 27-36. 
Mentzer J.T. 1988. "Forecasting With Adaptive Extended Exponential Smoothing." Joumal of the Academy of Marketing Science 16:3/4 (Fall): 62-70.

Mesak, Hi and William Mikhail. 1988. "Prelaunch Sales Forecasting of a New Industrial Product." Omega 16:1: 41-51.

Pan, Judy, Nichols, D.R. and O.M. Joy. 1977. "Sales Forecasting Practices of Large US Industrial Firms." Financial Management 6:3: 72-77.

Piercy, N.F. 1989. "The Power and Politics of Sales Forecasting: Uncertainty Absorption and the Power of the Marketing Department." Journal of the Academy of Marketing Science 17:2 (Spring): 109-120.

PoKemper, Stanley J. and E. Bailey. 1970. "Sales Forecasting Practices." The Conference Board, New York.

Prigogine, Ilya. 1989. “The Philosophy of Instability." Futures 21(August): 396-401.

Reilly, Robert F. 1980. "Developing a Sales Forecasting System." Managerial Planning (July/ August): 24-26.

Richter, Jake. 1988. "Forecasting Firms, Please Come Down to Earth." PC Week 5 (October): 57.

Rothe, James T. 1978. "Effectiveness of Sales Forecasting Methods." Industrial Marketing Management 7: 114-118.

Sales Management. 1987. “Sales Forecasting: Is Five Percent Error Good Enough?” (December): $41-48$.

Schnaars, Steven P. 1984. “Situational Factors Affecting Forecast Accuracy." Journal of Marketing Research 21 (August): 290-298.

. 1987. "The Use of Multiple Scenarios in Sales Forecasting." The International Journal of Forecasting 3: 405-419. . 1989. Megamistakes. New York: Free Press.

1989. "Where Forecasters Go Wrong." Across the Board 26 (Decem-

ber): $38-43$.

Sparkes, John R. and A.K. McHugh. 1984. "Awareness and Use of Forecasting Techniques in British Industry.” Joumal of Forecasting 3: 37-42.

Tersine, Richard J. 1980. "Logic for the Future: The Forecasting Function." Managerial Planning (March/April): 32-36. 
Fall 1993 Herbig, Milewicz \& Golden: The Mysteries of Forecasting

Tyebjee, Tyzoon T. 1987. "Behavioral Biases in New Product Forecasting." International Journal of Forecasting 3: 393-404.

Wheeler, David R. and Charles J.Shelley. 1987. "Toward More Realistic Forecasts for HighTechnology Products." Journal of Business and Industrial Marketing 2:3: 55-63.

Wheelwright, S.C. and D. Clarke. 1976. "Corporate Forecasting: Promise and Reality." Harvard Business Review (November/December).

Wright D.J. 1988. "Decision Support Oriented Sales Forecasting Methods." Journal of the Academy of Marketing Science 16:3/4 (Fall): 71-78. 